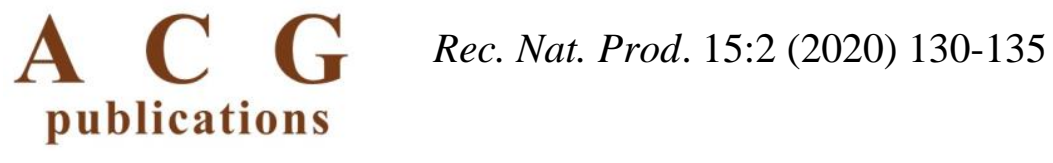

records of natural products

\title{
Chemical Investigation of a Co-Culture of Aspergillus fumigatus D and Fusarium oxysporum R1
}

\author{
Ronglu Yu $\odot^{1}$, Mingzhu Li $\oplus^{1}$, Yi Wang $\oplus^{1}$, Xuelian Bai $\odot^{2}$, \\ Jianwei Chen $\oplus^{1}$, Xingnuo Li $\odot{ }^{1}$, Hong Wang $\oplus^{1}$ and Huawei Zhang $\odot{ }^{1 *}$ \\ ${ }^{1}$ School of Pharmaceutical Sciences, Zhejiang University of Technology, Hangzhou 310014, China \\ ${ }^{2}$ College of Life and Environmental Sciences, Hangzhou Normal University, Hangzhou 311121,
} China

(Received July 13, 2020; Revised September 19, 2020; Accepted September 21, 2020)

\begin{abstract}
Chemical investigation of a co-culture of two endophytic fungi Aspergillus fumigatus D and Fusarium oxysporum R1 from two traditional medicinal plants, Edgeworthia chrysantha Lindl. and Rumex madaio Makino, led to isolation of a new amide $\mathbf{1}$ and six known compounds, including neovasinin (2), neovasifuranone B (3), N-(2-phenylethyl)acetamide (4), $\alpha$-linolenic acid (5), $\alpha$-elaeostearic acid (6), palmitoleic acid (7). On the basis of extensive spectroscopic analysis including 1D and 2D NMR, HR-ESI-MS and optical rotation measurement as well as comparison of literature data, chemical structure of $\mathbf{1}$ was unambiguous elucidated as $(S$, E)-methyl-2-(2,4-dimethylhex-2-enamido)acetate. Bioassay results indicated that none of these compounds exhibited strong inhibitory effect on three human pathogens Escherichia coli, Staphyloccocus aureus and Candida albicans with MIC values of $\geqslant 25 \mu \mathrm{M}$.
\end{abstract}

Keywords: Endophytic fungus; Aspergillus fumigatus D; Fusarium oxysporum R1; co-culture; amide; antimicrobial effect. (C) 2020 ACG Publications. All rights reserved.

\section{Introduction}

During the past almost two decades, phytochemical investigation of endophytic microbes had been worldwide carried out and resulted in isolation of more than 500 new functional chemicals, which exerted significant impact on development of new therapeutic agents and pesticides [1-2]. Recently, however, the speed of discovering new secondary metabolites from endophytes has been slowing down owing to consistent employment of conventional cultivation and isolation procedure. Microorganisms have potential biosynthetic gene clusters (BGCs) to make more compounds, which were left untapped under standard laboratory conditions [3-4]. A growing number of evidences indicated that the strategy of one strain many compounds (OSMAC) is a simple and powerful tool to enhance chemical diversity of microbes, such as changing medium composition and cultivation status, co-cultivation with other strain(s), adding enzyme inhibitor(s) and MSM biosynthetic precursor(s) [5]. Co-culture system can effectively alter individual microbial cellular physiology and access chemical diversity [6-10].

\footnotetext{
*Corresponding author: E-Mail: hwzhang@zjut.edu.cn; Phone (Fax): 0086-571-88320913
} 
In our continuous search for structurally unique and bioactive secondary metabolites from endophytic microbes, chemical study of a rice medium co-culture of two endophytic strains Aspergillus fumigatus D and Fusarium oxysporum R1 from two traditional medicinal plants, Edgeworthia chrysantha Lindl. and Rumex madaio Makino respectively, resulted in isolation of one new amide 1 and three known compounds neovasinin (2), neovasifuranone B (3), $N$-(2phenylethyl)acetamide (4) (Figure 1) and three well known fatty acids $\alpha$-linolenic acid (5), $\alpha$ elaeostearic acid (6) and palmitoleic acid (7). Interestingly, all these compounds were not detected in their axenic cultures [11-15]. Herein the isolation and structural elucidation of these compounds as well as antimicrobial effects are reported.

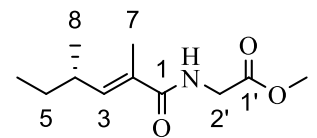

1<smiles>CCC(C)/C=C/[C@H]1OCc2c(oc(=O)c(C)c2O)[C@]1(C)O</smiles>

2

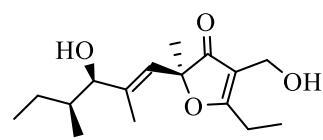

3

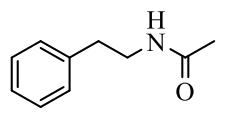

4

Figure 1. Chemical structures of compounds 1-4 from a co-culture of endophytic strains D and R1

\section{Materials and Methods}

\subsection{General}

All NMR experiments were run on a Bruker Avance DRX600 spectrometer (Bruker, Fällande, Switzerland) equipped with a $5 \mathrm{~mm}$ triple resonance (HCN) cold probe, using TMS as an internal standard. Optical rotation was detected on a JASCO P-2000 polarimeter (JASCO, Fukuoka, Japan). Melting points were recorded on an XRC-1 apparatus (Sichuan University Science and Education Instrument Factory, Chengdu, China). Ultraviolet (UV) spectrum was taken on Hitachi-UV-3000 spectrometer (Hitachi, Tokyo, Japan), and FT-IR spectrum was performed on Nexus 870 spectrometer (Thermo-Nicolet, Madison, WI, USA). ESI-MS and HR-ESI-MS data were obtained from an Agilent 6210 LC/TOF-MS spectrometer (Agilent Technologies, Santa Clara, CA, USA). Purification of all compounds was performed on Essentia LC-16P apparatus (Essentia, San Diego, CA, USA) equipped with a semi-preparative column (Phenomenex Hydro-RP, $250 \mathrm{~mm} \times 10 \mathrm{~mm}, 4 \mu \mathrm{m}$, Torrance, CA, USA) or an analytical column (Phenomenex Hydro-RP, $250 \mathrm{~mm} \times 4.6 \mathrm{~mm}, 4 \mu \mathrm{m}$, Torrance, CA, USA). Acetonitrile (Merck, Darmstadt, Germany), methanol (Merck) and $\mathrm{H}_{2} \mathrm{O}$ used in HPLC system were of chromatographic grade, and all other chemicals were analytical.

\subsection{Biological Material}

Two endophytic strains D and R1 were respectively isolated from two traditional medicinal plants Edgeworthia chrysantha Lindl. [16] and Rumex madaio Makino [17], and identified as Aspergillus fumigatus and Fusarium oxysporum according to their morphological characteristics and $18 S$ rDNA gene sequence, which had been reported before[18]. And these two strains were preserved in China General Microbiological Culture Collection Centre and coded as Nos. 17762 and 17763 , respectively.

\subsection{Fermentation and Isolation}

Endophytic strains D and R1 were inoculated separately into on slants of potato dextrose agar (PDA) for 7 days at $28{ }^{\circ} \mathrm{C}$. A proper amount of each fungal colony was inoculated into $500-\mathrm{mL}$ Erlenmeyer flask, which contained $250 \mathrm{~mL}$ potato dextrose broth (PDB), and shaken for 7 days at 200 $\mathrm{rpm}$ and $28{ }^{\circ} \mathrm{C}$, respectively. Then these seed cultures were simultaneously and respectively transferred into a $1000-\mathrm{mL}$ Erlenmeyer flask with sterilized rice $(160 \mathrm{~g})$ and tap water $(320 \mathrm{~mL})$ followed by co-cultivation at $28{ }^{\circ} \mathrm{C}$ for 30 days. 100 flasks of the rice medium co-culture were collected and extracted with ethyl acetate for 3 times. The organic layer was obtained by filtration 
through gauze and concentrated under vacuum at $40{ }^{\circ} \mathrm{C}$. The crude extract (approx. $90 \mathrm{~g}$ ) was dissolved in $100 \mathrm{~mL}$ of methanol to obtain a suspension, which was respectively extracted with $\mathrm{n}$ hexane and dichloromethane. The dichloromethane extraction layer was concentrated under reduced pressure to yield a crude extract $(27.09 \mathrm{~g})$ and then subjected to chromatography on a silica-gel (200 mesh) column eluted sequentially with dichloromethane and ethanol (100:0, 99:1, 98:2, 95:5, 90:10, 50:50; v/v) to obtain six fractions A-F. And the n-hexane extraction layer was evaporated at $25^{\circ} \mathrm{C}$ in vacuum to yield the extract $(45.49 \mathrm{~g})$ followed by separation on a preparative HPLC column (Phenomenex Gemini-NX C18, $50 \mathrm{~mm} \times 21.2 \mathrm{~mm}, 5 \mu \mathrm{m}$ ) to afford six fractions G-L according to our reported procedure [19].

Compound $4\left(3.6 \mathrm{mg}, \mathrm{t}_{\mathrm{R}}=15.5 \mathrm{~min}\right)$ was purified from fraction A using a semi-preparative HPLC column with $30 \% \mathrm{CH}_{3} \mathrm{CN} / \mathrm{H}_{2} \mathrm{O}$ with a flow rate of $3.0 \mathrm{~mL} / \mathrm{min}$ at $210 \mathrm{~nm}$. Fraction $\mathrm{B}$ was subjected to HPLC with an analytical column to afford compound $1\left(4.1 \mathrm{mg}, \mathrm{t}_{\mathrm{R}}=13.0 \mathrm{~min}\right)$ with $65 \%$ $\mathrm{CH}_{3} \mathrm{OH} / \mathrm{H}_{2} \mathrm{O}$ and compound $3(39.7 \mathrm{mg}$, $\mathrm{tR}=13.5 \mathrm{~min})$ with $40 \% \mathrm{CH}_{3} \mathrm{OH} / \mathrm{H}_{2} \mathrm{O}$, which the flow rate was set as $1.0 \mathrm{~mL} / \mathrm{min}$ at $210 \mathrm{~nm}$. While a large amount $\left(3624.4 \mathrm{mg}, \mathrm{t}_{\mathrm{R}}=13.0 \mathrm{~min}\right)$ of compound 2 was purified from fraction $\mathrm{C}$ with $65 \% \mathrm{CH}_{3} \mathrm{OH} / \mathrm{H}_{2} \mathrm{O}$ using the semi-preparative HPLC column. Fraction $\mathrm{J}$ was also separated on the semi-preparative HPLC column with $87 \% \mathrm{CH}_{3} \mathrm{CN} / \mathrm{H}_{2} \mathrm{O}$ to yield 5 $\left(46.5 \mathrm{mg}, \mathrm{t}_{\mathrm{R}}=7.8 \mathrm{~min}\right), \mathbf{6}\left(91 \mathrm{mg}, \mathrm{t}_{\mathrm{R}}=7.9 \mathrm{~min}\right)$ and $7\left(45.4 \mathrm{mg}, \mathrm{t}_{\mathrm{R}}=14.0 \mathrm{~min}\right)$.

\subsection{Antimicrobial Assay}

Antimicrobial test was carried out using three human pathogenic strains, Escherichia coli 25922, Staphyloccocus aureus ATCC 25923 and Candida albicans ATCC 10231, which were purchased from China Center for Type Culture Collection (CCTCC) by 96-well plate gradient dilution method [20-21]. The tested fungus was cultured in Sabouraud medium at $150 \mathrm{rpm}, 28^{\circ} \mathrm{C}$ for 48 hours, while the bacteria cultured in Luria-Bertani medium (LB) was incubated at $37^{\circ} \mathrm{C}$ for 24 hours at the same rotation speed, and the indicator strain was diluted with fresh medium with a cell density of $10^{5}$ $10^{6} \mathrm{cfu} / \mathrm{mL}$. All tested compounds were accurately weighed and dissolved with dimethyl sulphoxide (DMSO) while ampicillin and amphotericin B were used as the positive controls. A suitable volume of sample and microbial suspension was pipetted into a 96-well plate, which the first well had a volume of $200 \mu \mathrm{L}$ and a concentration of $100 \mu \mathrm{M}$. After pipetting evenly, $100 \mu \mathrm{L}$ was taken from the first hole and added to the next hole, and so on. The corresponding sample concentration per well was as follows: $100,50,25,12.5,6.25,3.125,1.56,0.78,0.39,0.195 \mu \mathrm{M}$. Three sets of parallel experiments were performed in each group, and the absorbance value of the indicated culture medium was detected by enzyme marker (Molecular Devices m5, MD, US). The minimum inhibitory concentration (MIC) was the lowest concentration of each compound that inhibited the growth of pathogenic microorganisms.

\section{Results and Discussion}

\subsection{Structure Elucidation}

Compound 1 was obtained as yellowish powder. It had a molecular formula of $\mathrm{C}_{11} \mathrm{H}_{19} \mathrm{NO}_{3}$ requiring 3 degrees of unsaturation, which was deduced from the positive molecule-ion peak at $\mathrm{m} / \mathrm{z}$ 236.1262 [M + Na $\left.{ }^{+}\right]$(calcd for $\mathrm{C}_{11} \mathrm{H}_{19} \mathrm{NO}_{3} \mathrm{Na}$ : 236.1257) in the HR-ESI-MS. Its strong IR bands at 1746, 1661, 1625 and $1207 \mathrm{~cm}^{-1}$ indicated the presence of chelated carbonyl group(s). The ${ }^{1} \mathrm{H}$ NMR spectrum (table 1) displayed compound 1 possesses four methyl signals at $\delta_{\mathrm{H}} 0.84(t, J=7.8,7.2 \mathrm{~Hz})$, $0.99(d, J=6.6 \mathrm{~Hz}), 1.87(d, J=1.2 \mathrm{~Hz})$ and $3.77(\mathrm{~s})$, and an olefinic proton at $\delta_{\mathrm{H}} 6.18(d, J=9.6 \mathrm{~Hz})$ and an amide hydrogen at $\delta_{\mathrm{H}} 6.34(\mathrm{brs})$. Detailed analysis of its ${ }^{13} \mathrm{C}$ NMR data and DEPT-135 spectrum (table 1) exhibited eleven carbon signals, including four methyls $\left(\delta_{\mathrm{C}} 12.01,12.87,19.95\right.$, $52.53)$, two methylenes $\left(\delta_{\mathrm{C}} 29.83,41.64\right)$, two methines $\left(\delta_{\mathrm{C}} 34.78,143.31\right)$ and three quaternary carbons $\left(\delta_{\mathrm{C}} 128.90,169.83,170.91\right)$, which accounted for three double-bond equivalents in $\mathbf{1}$. By careful inspection of the HMBC spectrum (Figure 2), the olefinic proton $\left(\mathrm{H}-3, \delta_{\mathrm{H}} 6.18\right)$ had remarkable HMBC correlations to $\mathrm{C}-1,5,7,8$, and the methoxyl $\left(\delta_{\mathrm{H}} 3.77\right)$ showed only correlation to C-1' $\left(\delta_{\mathrm{C}} 170.91\right)$. On basis of other key HMBC correlations from H-4 to C-2, H-6 to C-4, H-7 to C-1 
and C-3, H-8 to C-3 and C-5, and H-2' to C-1 and C-1' as well as no NOESY correlation between H-7 $\left(\delta_{\mathrm{H}} 0.99\right)$ and $\mathrm{H}-8\left(\delta_{\mathrm{H}} 1.87\right)$, the relative configuration of compound 1 was established as $(E)$-methyl-2(2,4-dimethylhex-2-enamido)acetate, which possessed only one stereogenic centre at C-4. Considering its similar optical rotation $\left([\alpha]_{\mathrm{D}}{ }^{25}=11.7\right)$ with that $\left([\alpha]_{\mathrm{D}}{ }^{25}=17.7\right)$ of fusarester $\mathrm{A}$, which was determined by electronic circular dichroism (ECD) calculation[22], the absolute configuration of the $\mathrm{C}-4$ in the molecule of $\mathbf{1}$ was determined as $S$. Therefore, the chemical structure of compound $\mathbf{1}$ was unambiguously established as $(S, E)$-methyl-2-(2,4-dimethylhex-2-enamido)acetate.

Biogenetically, compound $\mathbf{1}$ could have similar biosynthetic pathway with those of neovasinin derivatives [23], and be derived from a triketide precursor via condensation of three acetyl CoA followed by methylation and amidation [24] (Figure S13).

By careful comparison of the ${ }^{1} \mathrm{H},{ }^{13} \mathrm{C}$ NMR and ESI-MS data with literature, compounds 2-7 were characterized as neovasinin [25], neovasifuranone B [26], $N$-(2-phenylethyl)acetamide [27], $\alpha$ linolenic acid [28], $\alpha$-elaeostearic acid [29], palmitoleic acid [30], respectively.

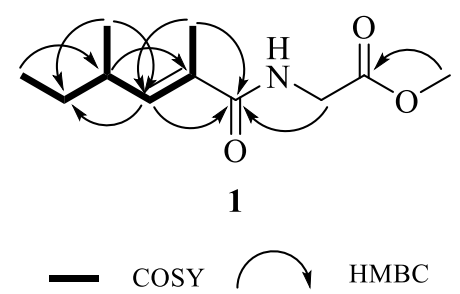

Figure 2. Key HMBC and ${ }^{1} \mathrm{H}^{-1} \mathrm{H}$ COSY correlations of compound 1

Table 1. ${ }^{1} \mathrm{H}$ NMR $(600 \mathrm{MHz}),{ }^{13} \mathrm{C}$ NMR $(151 \mathrm{MHz}), \mathrm{HMBC}$ and ${ }^{1} \mathrm{H}-{ }^{1} \mathrm{H} \mathrm{COSY}$ data $\left(\mathrm{CDCl}_{3}\right)$ for compounds 1 ( $\delta$ in ppm, $J$ in $\mathrm{Hz}$ )

\begin{tabular}{lllcc}
\hline Position & ${ }^{\mathbf{1}} \mathbf{H}$ & ${ }^{\mathbf{1 3}} \mathbf{C}$ & $\mathbf{H M B C}$ & ${ }^{\mathbf{}^{\mathbf{H}}-{ }^{-} \mathbf{H} \mathbf{C O S Y}}$ \\
\hline 1 & & $169.83(\mathrm{C})$ & $3,7,2^{\prime}$ & \\
2 & & $128.90(\mathrm{C})$ & 4 & \\
3 & $6.18(1 \mathrm{H}, \mathrm{d}, J=9.6)$ & $143.31(\mathrm{CH})$ & 7,8 & 4,7 \\
4 & $2.39(1 \mathrm{H}, \mathrm{m})$ & $34.78(\mathrm{CH})$ & 6 & 3 \\
5 & $1.35(2 \mathrm{H}, \mathrm{m})$ & $29.83\left(\mathrm{CH}_{2}\right)$ & 8 & 6 \\
6 & $0.84(3 \mathrm{H}, \mathrm{t}, J=7.8,7.2)$ & $12.01\left(\mathrm{CH}_{3}\right)$ & & 5 \\
7 & $1.87(3 \mathrm{H}, \mathrm{d}, J=1.2)$ & $12.87\left(\mathrm{CH}_{3}\right)$ & & 3 \\
8 & $0.99(3 \mathrm{H}, \mathrm{d}, J=6.6)$ & $19.95\left(\mathrm{CH}_{3}\right)$ & & 4 \\
$1^{\prime}$ & & $170.97(\mathrm{C})$ & $\mathrm{OCH}_{3}$ & \\
$2^{\prime}$ & $4.09(2 \mathrm{H}, \mathrm{d}, J=5.4)$ & $41.64\left(\mathrm{CH}_{2}\right)$ & & \\
$\mathrm{OCH}_{3}$ & $3.77(3 \mathrm{H}, \mathrm{s})$ & $52.53\left(\mathrm{CH}_{3}\right)$ & & \\
$\mathrm{NH}$ & $6.34(1 \mathrm{H}, \mathrm{br} \mathrm{s})$ & & & \\
\hline
\end{tabular}

\subsection{Antimicrobial Activity}

Bioassay results indicated that none of these compounds from the co-culture medium of strains $\mathrm{D}$ and R1 had potent antimicrobial activity against three human pathogens E. coli 25922, S. aureus ATCC 25923 and C. albicans ATCC 10231 owing to their MIC values of no less than $25 \mu \mathrm{M}$ (Table S1).

\section{Acknowledgments}

Financial supports from the National Key Research and Development Program of China (2018YFC0311002), the National Natural Science Foundation of China (41776139 and 81773628), the Fundamental Research Fund for the Provincial Universities of Zhejiang (RF-C2019002) and the Hangzhou Science and Technology Development Program of China (20170432B02) were greatly appreciated. 


\section{Supporting Information}

Supporting information accompanies this paper on http://www.acgpubs.org/journal/records-ofnatural-products

\section{ORCID}

Ronglu Yu: 0000-0003-4805-1301

Mingzhu Li: 0000-0003-0389-1104

Yi Wang: 0000-0002-5061-2270

Xuelian Bai: 0000-0003-3735-8164

Jinwei Chen: 0000-0001-5819-8441

Xingnuo Li: $0000-0002-7643-0459$

Hong Wang: 0000-0003-0058-060X

Huawei Zhang: 0000-0002-2430-3845

\section{References}

[1] H. W. Zhang, Y. C. Song and R. X. Tan (2006). Biology and chemistry of endophytes, Nat. Prod. Rep. 23, 753-771.

[2] H. W. Zhang, X. L. Bai, M. Zhang, J. W. Chen and H. Wang (2018). Bioactive natural products from endophytic microbes, Nat. Prod. J., 8, 86-108.

[3] G. L. Challis (2008). Genome mining for novel natural product discovery, J. Med. Chem, 51, 2618-2628.

[4] S. Kirstin and H. Christian (2009). Triggering cryptic natural productbiosynthesis in microorganisms, Org. Biomol. Chem. 7, 1753-1760.

[5] R. Pan, X. L. Bai, J. W. Chen, H. W. Zhang and H. Wang (2019). Exploring structural diversity of microbe secondary metabolites using OSMAC Strategy: A literature review, Front. Microbiol. 10, Article Number 294 (20 pages).

[6] M. A. Abdalla, S. Sulieman and L. J. McGaw (2017). Microbial communication: A significant approach for new leads, S. Afr. J Bot. 113, 461-470.

[7] M. F. Abdelwahab, T. M. Kurtán, Attila, W. E. G. Müller, M. A. Fouad, M. S. Kamel, Z. Liu, W. Ebrahim, G. Daletos and P. Proksch (2018). Induced secondary metabolites from the endophytic fungus Aspergillus versicolor through bacterial co-culture and OSMAC approaches, Tetrahedron Lett. 59, 2647-2652.

[8] K. Ueda and T. Beppu (2017). Antibiotics in microbial co-culture, J. Antibiot. 70, 361-365.

[9] R. X. Tan and W. X. Zou (2001). Endophytes: a rich source of functional metabolites, Nat. Prod. Rep. 18, 448-459.

[10] Z. Q. Tan, H. Y. Yin, D. C. W. Lee and K. Karisnan (2019). Co-culture systems for the production of secondary metabolites: Current and future prospects, Open Biotech. J. 13,18-26.

[11] J. W. Chen, X. L. Bai, Y. Hua, H. W. Zhang and H. Wang (2019). Fusariumins C and D, two novel antimicrobial agents from Fusarium oxysporum ZZP-R1 symbiotic on Rumex madaio Makino, Fitoterapia 134, 1-4.

[12] H. W. Zhang, X. L. Bai and H. Wang (2017). Isolation and identification of an antimicrobial and cytotoxic chlorated perylenequinone from the symbiotic fungus Aspergillus fumigatus D, Biochem. Pharmacol. 139, 110-110.

[13] H. W. Zhang, Z. P. Zhao, J. W. Chen, X. L. Bai and H. Wang (2018). Tricycloalternarene analogs from a Symbiotic Fungus Aspergillus sp. D and their antimicrobial and cytotoxic effects, Molecules 23, 855 (7 pages).

[14] H. W. Zhang, C. F. Ruan, X. L. Bai, J. W. Chen and H. Wang (2018). Heterocyclic alkaloids as antimicrobial agents of Aspergillus fumigatus D endophytic on Edgeworthia chrysantha, Chem. Nat. Compd+. 54, 411-414.

[15] X. L. Bai, R. L. Yu, M. Z. Li and H. W. Zhang (2019). Antimicrobial assay of endophytic fungi from Rumex madaio and chemical study of strain R1, Bangl. J. Pharmacol. 14, 129-135.

[16] L. Q. Sheng, J. Z. Yan, S. Q. Tong and Y. J. Ye (2009). Chemical constituents of Edgeworthia chrysantha Lindl, China J. Chin. Mater. Med. 4, 495-496 (in Chinese).

[17] Y. L. Wei, J. Wu and Y. P. Deng (2015) Optimization of extraction process of total flavonoids from Rumex madaio Makino (in Chinese), Food Res. Dev. 14, 20-24 (in Chinese). 
[18] H. W. Zhang, C. Ying and Y.F. Tang (2014). Four ardeemin analogs from endophytic Aspergillus fumigatus SPS-02 and their reversal effects on multidrug-resistant tumor cells, Chem. Biodivers, 11, 85-91.

[19] H. W. Zhang, S. T. Loveridge, K. Tenney and P. Crews (2015) A new 3-alkylpyridine alkaloid from the marine sponge Haliclona sp. and its cytotoxic activity, Nat. Prod. Res., 11, 1262-1265.

[20] I. Wiegand, K. Hilpert and R. E. W. Hancock (2008). Agar and broth dilution methods to determine the minimal inhibitory concentration (MIC) of antimicrobial substances, Nat. Protoc. 3, 163-175.

[21] H. S. Lee, H. H. Song, J. H. Jeong, C. G. Shin and S. U. Choi and C. Lee (2008). Cytotoxicities of enniatins H, I, and MK1688 from Fusarium oxysporum KFCC11363P, Toxicon 51, 1178-1185.

[22] J. J. Gong, C. M. Chen, S. Y. Mo, J. J. Liu, W. J. Wang, Y. Zang, H. Q. Li, C. W. Chai, H. C. Zhu, Z. X. Hu, J. P. Wang and Y. H. Zhang (2019). Fusaresters A-E, new gamma-pyrone-containing polyketides from fungus Fusarium sp. Hungcl and structure revision of fusariumin D, Org. Biomol. Chem. 17, 5526-5532.

[23] T. Furumoto, T. Hamasaki and H. Nakajima (1999). Biosynthesis of phytotoxin neovasinin and its related metabolites, neovasipyrones $\mathrm{A}$ and $\mathrm{B}$ and neovasifuranones $\mathrm{A}$ and $\mathrm{B}$, in the phytopathogenic fungus Neocosmospora vasinfecta, J. Chem. Soc. Perkin Trans. 1 30, 131-135.

[24] Z. Wasil, Pahirulzaman, K. A. K. C. Butts, T. J. Simpson, C. M. Lazarus and R. J. Cox (2013). One pathway, many compounds: heterologous expression of a fungal biosynthetic pathway reveals its intrinsic potential for diversity, Chem. Sci. 4, 3845-3856.

[25] H. Nakajima, K. Nishimura, T. Hamasaki, Y. Kimura and S. Udagawa. (1987). Structure of neovasinin, a new metabolite produced by the fungus, neocosmospora-vasinfecta - smith,e.f. and its biological-activity to lettuce seedlings, Agr. Bio. Chem. 51, 2831-2833.

[26] T. Furumoto, K. Fukuyama, T. Hamasaki and H. Nakajima (1995). Neovasipyrones and neovasifuranones 4 new metabolites related to neovasinin, a phytotoxin of the fungus, Neocosmospora-vasinfecta, Phytochemistry 40, 745-751.

[27] Y. M. Liang, Y. U. Yang, G. K. Wang, J. S. Liu, P. L. Zhang, M. A. Zong, H. T. Liu and G. Wang. (2017). Study on secondary metabolites of endophytic fungus Fusarium lactis from Dendrobium huoshanense, Chin. Tradit. Herb. Drugs 48, 4608-4616 (in Chinese).

[28] Q. Yang, S. B. Wang, J. B. Wang, Y. H. Xie, Z. Liu, J. Y. Sun, S. Miao and Q. Miao (2008). Study on extraction and identification of $\alpha$-linoienc acid from Semen Zanthoxyli bungeani, Chin. J New Drugs, 17, 318-320. (in Chinese).

[29] T. P. Hilditch and J. P. Riley (1945). Spectrographic determination of linoleic, linolenic, and eleostearic acids, Analyst, 70, 68-74.

[30] K. A. Bogucka and M. Janyszek (2010). Fatty acids composition of fruits of selected central European sedges, Carex L. (Cyperaceae), Grasas Aceites 61, 165-170.

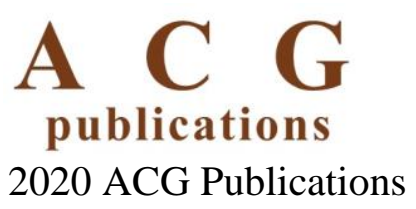

